\title{
Angiosarcoma pulmonar
}

\section{Sr. Director:}

Los angiosarcomas son tumores vasculares de naturaleza maligna que representan del $1-2 \%$ de todos los sarcomas ${ }^{1}$, y principalmente afectan al pulmón de forma metastásica, siendo su origen primario extremadamente raro. Se presenta el caso de un paciente que presentó un derrame pleural como manifestación inicial y cuyas pruebas complementarias llevaron al diagnóstico de angiosarcoma epitelioide pulmonar.

El paciente, varón de 78 años de edad, con antecedentes personales de hipertensión arterial, diabetes mellitus tipo II en tratamiento con antidiabéticos orales y tabaquismo de 40 paquetes·año, consultó refiriendo disnea y dolor en el costado izquierdo asociado a astenia, anorexia y pérdida de peso de varios meses de evolución. Las pruebas complementarias mostraron una anemia normocítica normocrómica (hemoglobina de $11 \mathrm{gr} / \mathrm{dL}$ ), presencia de leucocitosis de $15 \times 10^{9} / \mathrm{L}$ y una bioquímica sanguínea general normal. La radiografía de tórax reveló un agrandamiento hiliar ipsilateral y un derrame pleural izquierdo submasivo que disminuyó tras su evacuación parcial. La toracocentesis mostró un líquido serohemático con un $\mathrm{pH}$ de 7,39, proteínas de 4,19 $\mathrm{mg} / \mathrm{L}$ y una fórmula a expensas de mononucleares. Tanto el cultivo del líquido pleural como el estudio citológico fueron negativos. En la tomografía computerizada (TC) se observaron un derrame pleural izquierdo, una masa subcarinal interpretada como conglomerado adenopático necrótico, y una masa hiliar izquierda, consolidación del parénquima del lóbulo superior que contactaba e infiltraba la pleura parietal (Figura 1), sin hallazgos relevantes en el abdomen o pelvis. Se le efectuó una pleuroscopia don-

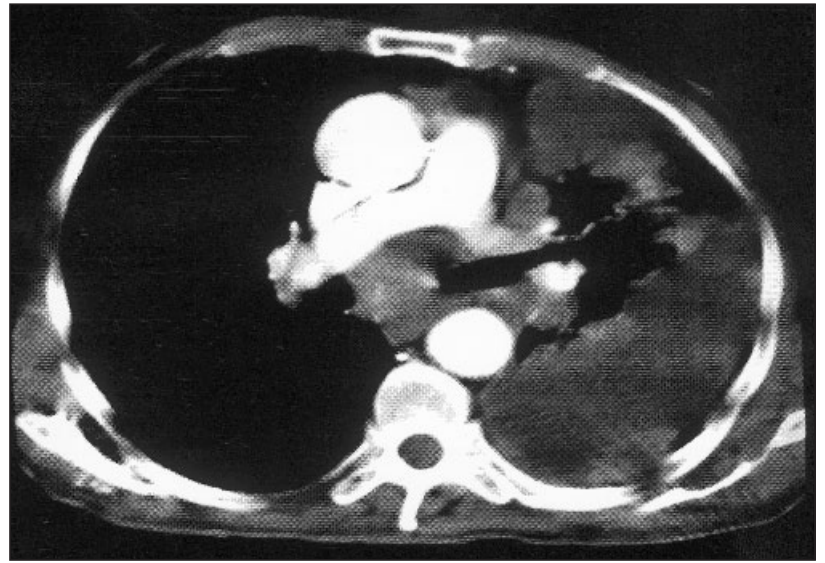

Figura 1. Derrame pleural izquierdo, conglomerado adenopático necrótico, y una masa hiliar izquierda junto con consolidación del parénquima del lóbulo superior que contacta e infiltra la pleura parietal.

de se objetivó una consolidación del parénquima pulmonar de ambos lóbulos que infiltraba la pleura, tanto visceral como parietal. El resultado del estudio anatomopatológico de las biopsias describió un patrón de crecimiento sólido con marcada atipia citológica y elevada actividad divisional (5-7 mitosis/campo de 40x), el estudio de inmunohistoquimia reveló positividad par CD31, vicentina, antígeno epitelial de membrana y factor antiproteína VIII, siendo negativa para CD34, antígeno carcinoembrionario y CD15; todos estos hallazgos concordaban con el diagnóstico de un angiosarcoma epitelioide pulmonar.

A pesar de que los angiosaromas cuando afectan al pulmón lo hacen como enfermedad metastásica ${ }^{2}$ de un primario situado a distancia, en ocasiones, la localización pulmonar puede ser primaria, como así lo atestiguan varios casos en la literatura ${ }^{3-5}$, sin em- 
bargo, es importante reseñar que desde el punto de vista clinicopatológico las formas primarias y metastásicas pueden ser superponibles, siendo en ocasiones prácticamente indistinguibles, por lo que se recomienda antes de reconocer a un angiosarcoma pulmonar como primario descartar otros posibles localizaciones primarias ${ }^{6}$. En este caso, la homolateralidad de la enfermedad, la afectación adenopática mediastínica junto a la masa hiliar, el haber descartado orígenes primarios próximos (arteria pulmonar, pericardio o corazón) por TC y pleuroscopia, estarían a favor de un origen primario de la enfermedad, si bien, el hecho de presentar dos lesiones pulmonares, aunque una de ellas fuese hiliar, la falta de búsqueda selectiva de otros asientos primarios posibles, como la piel y tejidos blandos, no permitiría descartar que la enfermedad fuese metastásica, pues debido a que el paciente debutó con una clínica principalmente respiratoria, hizo que el diagnóstico se centrase en el tórax, obviando la búsqueda de otros posibles focos de enfermedad. Por todo ello, es por lo que consideramos que quizás nos hallásemos frente a un angiosarcoma pulmonar primario, una auténtica rareza, pues sólo se han comunicado unos 10 casos en la literatura.

\author{
J. M. Hernández Pérez ${ }^{1}$, E. Martín Díaz ${ }^{2}$, \\ E. Martín Rodríguez ${ }^{2}$ \\ ${ }^{1}$ Servicio de Neumología \\ ${ }^{2}$ Servicio de Cirugía Torácica \\ Hospital Universitario Ntra. Sra. de Candelaria \\ Sta. Cruz de Tenerife
}

\section{Bibliografía}

1. López L, Iriberri M, Cancelo L, Gómez A, Uresandi F y Atxotegui V. Hemoptisis de repetición secundarias a un angiosarcoma epitelioide generalizado. Arch Bronconeumol 2004;40(4):188-90.

2. García M, González T, Escobar J, Seco A, Celorio C, Rodríguez J. Angiosarcoma pulmonar metastático. An Med interna 2004;21:27-30.

3. Sheppard MN, Hansell DM, Du Bois RM, Nicholson AG. Primary epitheloid angiosarcoma of the lung presenting as pulmonary hemorrhage. Hum Pathol 1997;28(3):383-5.

4. Kojima K, Okamoto I, Ushijama S, Yoshinaga T, Kitaoka M, Suga M and Sasaki Y. Succesful treatment of primary pulmonary angiosarcoma. Chest 2003;124:2397-2400.

5. Atasoy C, Fitoz S, Yigit T, Atasoy P, Erden I and Akyar S. Radiographic, CT and MRI finfings in primary pulmonary angiosarcoma. Journal of Clinical Imaging 2001; 25:337340.

6. Pastor AJ y Riu F. Hemoptisis e infiltrados pulmonares en una mujer de 22 años. Med Clin (Barc) 1999;112:349-55.

\author{
Correspondencia: \\ Dr. J. M. Hernández Pérez \\ Servicio de Neumología \\ Hospital Universitario Nuestra Señora de Candelaria \\ Carretera de El Rosario, 145 \\ E-38010 Santa Cruz de Tenerife \\ E-mail: jmherper@terra.es
}

